\title{
Knowledge and Attitude Practice (KAP) of Rickets Disease among Mothers in KSA
}

\author{
${ }^{1}$ Fahad Saleh Alsuwat, ${ }^{1}$ Nouf Jafer Alzahrani, ${ }^{1}$ Mohammed Ateih Awwad Alsofyani, ${ }^{2}$ Reem \\ Mohammed Alshamrani, ${ }^{3}$ Nadia Abaidullah Ahmed, ${ }^{1}$ Abdulrahman Talal Qasim, ${ }^{4}$ Samia \\ Mohammad Babi, ${ }^{1}$ Emad Ruddah M. Alsofyani
}

\author{
${ }^{1}$ Taif University, ${ }^{2}$ King Abdulaziz University, ${ }^{3}$ Imam Abdulrahman Bin Faisal University, ${ }^{4}$ National Ribat University \\ alshafa2013falcon@hotmail.com
}

\begin{abstract}
Background: Rickets is one of the emerging diseases around the world and its records have been frequently increased among Saudi children.

Objective: Our aim of the study was to discuss and improve the knowledge and the awareness of mothers in the Kingdom of Saudi Arabia about rickets disease and its environmental and nutritional risk factors.

Methods: We conducted this cross-sectional retrospective Study at the maternal Children Hospital in Taif, Saudi Arabia. Data were collected using a pre-specified questionnaire after obtaining the patients consent. SPSS software was used to analyze the data.

Results: We included 150 mothers with their children. There were $146(97.3 \%)$ of the children with vitamin D deficiency.

Conclusion: In Saudi Arabia, there is a need for campaigns that spread awareness among mothers and young adult females about the importance of vitamin $\mathrm{D}$, diets containing adequate levels of it as well the risk factors that cause its deficiency.
\end{abstract}

Keywords: Vitamin D, rickets, mothers, awareness, knowledge, children, Saudi Arabia.

\section{INTRODUCTION}

Vitamin D insufficiency can come about because of insufficient presentation to daylight; malabsorption; quickened catabolism from specific medicines; and, in newborn children, the negligible measure of vitamin $\mathrm{D}$ found in bosom drain. In youngsters, vitamin D lack can bring about rickets, which exhibits as bowing of the legs; in grown-ups, it brings about osteomalacia, which introduces as an ineffectively mineralized skeletal framework ${ }^{(1)}$.

Researches in Saudi Arabia have studied Osteomalacia and Rickets in different ages and both sexes5, 6 . Significantly more women than men suffered from vitamin D deficiency this was explained by the fact that men are more exposed to sunlight than women ${ }^{(2)}$.

Living in the Eastern area in Saudi Arabia, females, 16-19 years old, low financial class, large and absence of omega 3 supplements were hazard factors in understudies. Representatives living in the Eastern locale, females, center wage class, carbonated soda pop buyers, and absence of multivitamin supplements were at higher hazard ${ }^{(3)}$.

Around $96.7 \%$ and $78.2 \%$ of females and guys were insufficient in vitamin $\mathrm{D}$, individually. No adequate vitamin $D$ female subject was perceived. The predominance of vitamin D insufficiency in kids school from Makkah was high and the inadequacy was higher in females than guys. The principle explanation behind vitamin D inadequacy was the confinement to daylight introduction $^{(4)}$.

Nutritional rickets is as yet predominant in Saudi Arabia with the essential etiology being vitamin D lack. The majority of our patients were below the age of 14 months and none was more youthful than a half year of age. Male newborn children dwarfed the females 2:1. There is no obvious clarification for this finding however this has been additionally seen in a few reports ${ }^{(5)}$.

The consciousness of vitamin D and daylight in youngsters should be enhanced by the arrangement of prepared doctors and teachers. Making more regions where young ladies can reveal uninhibitedly amid routine works and open air exercises will help expand their vitamin D levels ${ }^{(6)}$.

\section{METHODS}

\section{Study design:}

This study is a retrospective, descriptive and comparative study with systemic randomized selection among all mothers in mother-children hospital at Taif city.

We included Saudi mothers in KSA of all age groups who have children younger than or at age 6 months and mothers who were willing to participate in this study; we excluded as well as mothers who did not have children and mothers who declined to participate in this study Data was collected by distributing a pre-specified 
questionnaire through the Maternal Children hospital-Taif, Each questionnaire included those main titles: Information about the child. Information about the mothers and their knowledge on vitamin $\mathrm{D}$.

Statistical analyses were performed using SPSS24 for Windows (SSPSInc., Chicago, IL,USA). P-value was considered significant when it was less than 0.05 .

\section{Research ethics:}

The ethical approval of Research ethics committee at Taif University approved this study. Participation was voluntary, and participants were told that they could withdraw from the study at any time. All their personal information will be confidential and the results will be published as a total. Informed consent was obtained.

\section{RESULTS}

We included150 mothers that visited the Maternal Children hospital-Taif, Saudi Arabia with their children. There were 79 (52.7\%)male children and71 $(47.3 \%)$ female children. One hundred and thirty-three (133)(90.7\%)mothers feed their children in addition to either bottle feeding or just breastfeeding ; and 17 (11.3\%) use bottle feeding only. Sixty-three(63)(42.0\%)children were found to have Vitamin D deficiency(table 1).

In table 2 ,we summarized the baseline characteristics of mothers who participated in this study. The most preventable age group was between 20-30 years, 49.3\% were academic and $92.7 \%$ were Saudi mothers. Of the participating mothers, $35.3 \%$ have 3 or 4 children.

In table 3, we reported their answers regarding what knowledge they had about Rickets disease. Sixty-eight(68\%) thought that sun rays were the best source of vitamin Dand50.7\% reported that vitamin D was only important for growth.

Table 4 demonstrate the results of questions about the awareness of the supplements, what can be its alternative and the necessity of its uptake. However, we found 85

Mothers never used it with their children and the mothers who did used it followed different duration, doses and obtained it from different sources(table 5).
Table (1): Baseline characteristics of children.

\begin{tabular}{|l|c|}
\hline \multicolumn{1}{|c|}{ Variable } & Value \\
\hline Children's Gender (\%): & $79(52.7)$ \\
Male & $71(47.3)$ \\
Female & $136(90.7)$ \\
\hline Pregnancy duration (\%) & $14(9.3)$ \\
$>8$ months & \\
$<8$ months & $133(88.7)$ \\
\hline Breastfeeding(\%) & $17(11.3)$ \\
Yes & \\
No & $63(42.0)$ \\
\hline Type feeding(\%) & $17(11.3)$ \\
Breast feeding only & $25(16.7)$ \\
Bottle feeding only & $30(20.0)$ \\
Both but breast feeding more & $15(10.0)$ \\
Both but bottle feeding more & \\
Both the same & $111(74.0)$ \\
\hline Health problems (\%) & $3(2.0)$ \\
Healthy & $18(12.0)$ \\
Bone disease & $9(6.0)$ \\
Liver disease & $9(6.0)$ \\
Kidney disease & \\
Other & $63(42.0)$ \\
\hline Vitamin D deficiency(\%) & $83(55.3)$ \\
Yes & $4(2.7)$ \\
No & \\
No idea & \\
\hline
\end{tabular}

Table (2): Baseline characters of participating mothers.

\begin{tabular}{|l|c|}
\hline \multicolumn{1}{|c|}{ Variable } & Value \\
\hline Age(\%) & $7(4.7)$ \\
Under20 & $68(45.3)$ \\
$(20-30)$ & $42(28.0)$ \\
$(31-40)$ & $23(15.3)$ \\
$(41-45)$ & $10(6.7)$ \\
$>45$ & \\
\hline Education(\%) & $17(11.3)$ \\
Uneducated & $59(39.3)$ \\
High school or less & $74(49.3)$ \\
Academic & \\
\hline occupation(\%) & $90(60)$ \\
House wife & $23(15.3)$ \\
Student & $37(24.7)$ \\
Work & $139(92.7)$ \\
\hline Nationality & $11(7.3)$ \\
Saudi & \\
Non-Saudi & $46(30.7)$ \\
\hline Children(\%) & $53(35.3)$ \\
One & $33(22.0)$ \\
(2-3) & $14(9.3)$ \\
(4-5) & $4(2.7)$ \\
(6-7) & $52(34.7)$ \\
More than 7 & $58(38.7)$ \\
\hline Vitamin D(\%) & $27(18.0)$ \\
Deficiency during pregnancy & \\
Using Vitamin D supplement during & \\
pregnancy & \\
Using Vitamin D supplement during & \\
Lactation & \\
\hline & \\
\hline
\end{tabular}


Table (3): Knowledge and awareness.

\begin{tabular}{|l|c|}
\hline \multicolumn{1}{|c|}{ Variable } & Value \\
\hline Best source of vitamin D(\%) & $102(68.0)$ \\
Sun & $31(20.7)$ \\
Mother's milk & $2(1.3)$ \\
Industrial milk & $4(2.7)$ \\
Supplements & $11(7.3)$ \\
No idea & \\
\hline Vitamin D importance(\%) & $76(50.7)$ \\
Growth & $8(5.3)$ \\
Immunity & $53(35.3)$ \\
Both & $13(8.7)$ \\
No idea & \\
\hline Natural sources(\%) & $73(48.7)$ \\
Egg yolk, lamb liver, salmon & $14(9.3)$ \\
Red meat, egg white, nut & $23(15.3)$ \\
Vegetables, fruits, rice & $12(8.0)$ \\
Vegetables, nuts & $28(18.7)$ \\
No idea & \\
\hline Vitamin D deficiency sequences $(\%)$ & $85(56.7)$ \\
Rickets & $3(2.0)$ \\
Diabetes mellitus & $5(3.3)$ \\
Bronchial Asthma & $22(14.7)$ \\
Immunodeficiency & $16(10.7)$ \\
All the above & $19(12.7)$ \\
No idea & $100(66.7)$ \\
\hline Exposure of child to sun rays $(\%)$ & $50(33.3)$ \\
Yes & \\
No & \\
\hline & \\
\hline
\end{tabular}

Table (4): Awareness about vitamin D supplements.

\begin{tabular}{|l|c|}
\hline \multicolumn{1}{|c|}{ Variable } & Value \\
\hline Taking vitamin D supplements if prescribed (\%) & \\
Agree & $146(97.3)$ \\
Disagree & $1(0.7)$ \\
No idea & $3(2.0)$ \\
\hline Need for supplements with breastfeeding(\%) & \\
Need & $74(49.3)$ \\
No need & $51(34.0)$ \\
No idea & $25(16.7)$ \\
\hline Need for supplements with sun exposure (\%) & \\
Need & $97(64.7)$ \\
No need & $32(21.3)$ \\
No idea & $21(14.0)$ \\
\hline
\end{tabular}

Table (5): The usage of vitamin D supplements.

\begin{tabular}{|l|c|}
\hline \multicolumn{1}{|c|}{ Variable } & Value \\
\hline Using of vitamin D supplements for Children (\%) & \\
Yes & $65(43.3)$ \\
No & $85(56.7)$ \\
\hline Usage of vitamin D supplements (\%) & \\
None & $85(56.7)$ \\
First month & $16(10.7)$ \\
second month & $7(4.7)$ \\
Third month & $10(6.7)$ \\
Fourth & $10(6.7)$ \\
(5th,6th) & $22(14.7)$ \\
\hline How many doses of vitamin D supplements (\%) & \\
None & $85(56.7)$ \\
once/day & $40(26.7)$ \\
Less than 3/week & $10(6.7)$ \\
3/week & $10(6.7)$ \\
Other & $5(3.3)$ \\
\hline Duration of using vitamin D supplements(\%) & \\
None & $85(56.7)$ \\
Less than seven days & $10(6.7)$ \\
Less than one month & $13(8.7)$ \\
more than three months & $25(16.7)$ \\
Less than three months & $14(9.3)$ \\
Other & $3(2.0)$ \\
\hline When forget the dose (\%) & \\
None & $85(56.7)$ \\
Next dose & $22(14.7)$ \\
double dose & $7(4.7)$ \\
Give the baby when I remember & $33(22.0)$ \\
Other & $3(2.0)$ \\
\hline Site of getting it(\%) & $85(56.7)$ \\
Non & $32(21.3)$ \\
PHC & $21(14.0)$ \\
Private PHC & $9(6.0)$ \\
Pharmacy & $3(2.0)$ \\
Other & \\
\hline
\end{tabular}

\section{DISCUSSION}

The fundamental factor related with its predominance was natural and social shirking of introduction to the sun, which sparkles all the year round $^{(7)}$.

In this study, almost $66.7 \%$ of mothers said they expose their children to sunlight as they think it's an important source of vitamin D.

The familiarity with vitamin $\mathrm{D}$ and daylight in kids should be enhanced by arrangement of prepared doctors and teachers. Making more territories where young ladies can reveal unreservedly amid routine works and outside exercises will help build their vitamin D levels ${ }^{(8)}$.

The overview uncovered extensive numbness and disarray about the part of daylight in vitamin D generation, and the capacity and wellsprings of vitamin D.among respondents who realized that vitamin $\mathrm{D}$ was useful for bone wellbeing and that daylight was a wellspring of vitamin $\mathrm{D}^{(9)}$. 
In Our study there is misunderstood about role and natural sources of vit D among our study group and The majority of them believe importance use Vit D supplements with breastfeeding and sun exposure to prevent Vit D depletion.

The most interesting feature of the present study was that it was conducted in Saudi Arabia, where screening studies are nearly non-existent. We also discussed new topic which could highlight the way to other researchers to intensify the research studies in this concern to increase and improve the awareness among Saudi society as well gaining more scientific information about this harmful disease. We faced some limitations such as the small sample size and lack of funding to add more scientific centers from other cities.

\section{CONCLUSION}

At this time, there are no obvious recommendations for the early detection of Rickets. However, both patients and physicians need to be aware of the problem and the importance of maintaining vitamin D levels. We also need to increase and improve knowledge of vitamin D sources as well as the risk factors leading to its deficiency.

\section{REFERENCES}

1. Tangpricha V, Khazai NB (2017): Vitamin D deficiency and related disorders. Medscape, available at: https:// emedicine. medscape. com/ article/ 128762-overview

2. Ward L, Gaboury I, Ladhan M, Zlotkin S (2007): Vitamin D-deficiency rickets among children in Canada. Canadian Medical Association Journal, 177(2): 161-166.

3. Siddiqui AM, Kamfar HZ (2007): Prevalence of vitamin D deficiency rickets in adolescent school girls in Western region, Saudi Arabia. Saudi medical journal, 28(3): 441-444.

4. Kensarah OA, Azzeh FS (2012): Vitamin D status of healthy school children from western Saudi Arabia. Pakistan Journal of Nutrition, 11(3): 288-292.

5. Al-Atawi MS, Al-Alwan IA, Al-Mutair AN, Tamim HM, Al-Jurayyan NA (2009): Epidemiology of nutritional rickets in children. Saudi Journal of Kidney Diseases and Transplantation, 20(2): 260-265.
6. Al-Saleh Y, Al-Daghri NM, Khan N, Alfawaz H, Al-Othman AM, Alokail MS, Chrousos GP (2015): Vitamin D status in Saudi school children based on knowledge. BMC pediatrics, 15(1): 53-57.

7. Elidrissy AT, Sandokji AM, Al-Magamsi MS, Al-Hawsawi ZM, Al-Hujaili AS, Babiker NH, Yousif AM (2012): Nutritional rickets in Almadinah Almunawwarah: Presentation and associated factors. Journal of Taibah University Medical Sciences, 7(1): 3540.

8. Al-Saleh Y, Al-Daghri NM, Khan $\mathbf{N}$, Alfawaz H, Al-Othman AM, Alokail MS, Chrousos GP (2015): Vitamin D status in Saudi school children based on knowledge. BMC pediatrics, 15(1): 53-57.

9. Kung, AW, Lee KK (2006): Knowledge of vitamin $\mathrm{D}$ and perceptions and attitudes toward sunlight among Chinese middle-aged and elderly women: a population survey in Hong Kong. BMC public health, 6(1): 226231. 